Available online at GSC Online Press Directory

GSC Biological and Pharmaceutical Sciences

e-ISSN: 2581-3250, CODEN (USA): GBPSC2

Journal homepage: https://www.gsconlinepress.com/journals/gscbps

(REVIEW ARTICLE)

\title{
Altitudinal variation of sexual size dimorphism in ground beetle Carabus odoratus
} Shill.

Tatyana Ananina 1,2, ${ }^{*}$, Raisa Sukhodolskaya ${ }^{3}$ and Anatoliy Saveliev ${ }^{4}$

1 State Budgetary Establishment "Zapovednoe Podlemorie", Komsomolskaya str. 44 - 64, Ulan Ude, 670045, Russian Federation.

2 Institute of General and Experimental Biology SB RAS Sakhyanovoj str. 6, Ulan-Ude, 670047, Russian Federation.

${ }^{3}$ State Budgetary Establishment Research Institute for Problems of Ecology and Mineral Wealth, Daurskaya str. 28, Kazan Tatarstan 420087 Russian Federation.

${ }^{4}$ Kazan (Volga Region), Federal University, Kremlevskaya str. 18, Kazan-2, Tatarstan, Russian Federation.

Publication history: Received on 08 July 2020; revised on 04 August 2020; accepted on 06 August 2020

Article DOI: https://doi.org/10.30574/gscbps.2020.12.2.0216

\begin{abstract}
Samples of Carabus odoratus barguzinicus Shil. collected in different altitudes of Barguzin Mountain Range at the northeast part of Baikal Lake (N 54 20'; E 109 30', Russia). In total eight populations were analyzed, two in each belt: Coast, Low-, Middle- and High Mountains (455-460, 500-700, 701-1300, 1301-1700 m above sea level). Morphometric measurements included six traits (elytra length and width, pronotum length and width, head length, and the distance between eyes) of 1300 specimens. Sexual size dimorphism (SSD) in Carabus odoratus was female-biased. Its value was significant and more pronounced in Low- and High mountains and varied from 0.01 to 0.1 in different traits and at different altitudes. The largest values of SSD was at Low- and High mountains. The latter considered the most favorable biotopes to the species studied. RMA II method resulted in positive Intercepts in most traits treated. That demonstrated the higher sensitivity of females to environmental conditions and that Carabus odoratus follows the opposite Rensch's rule.
\end{abstract}

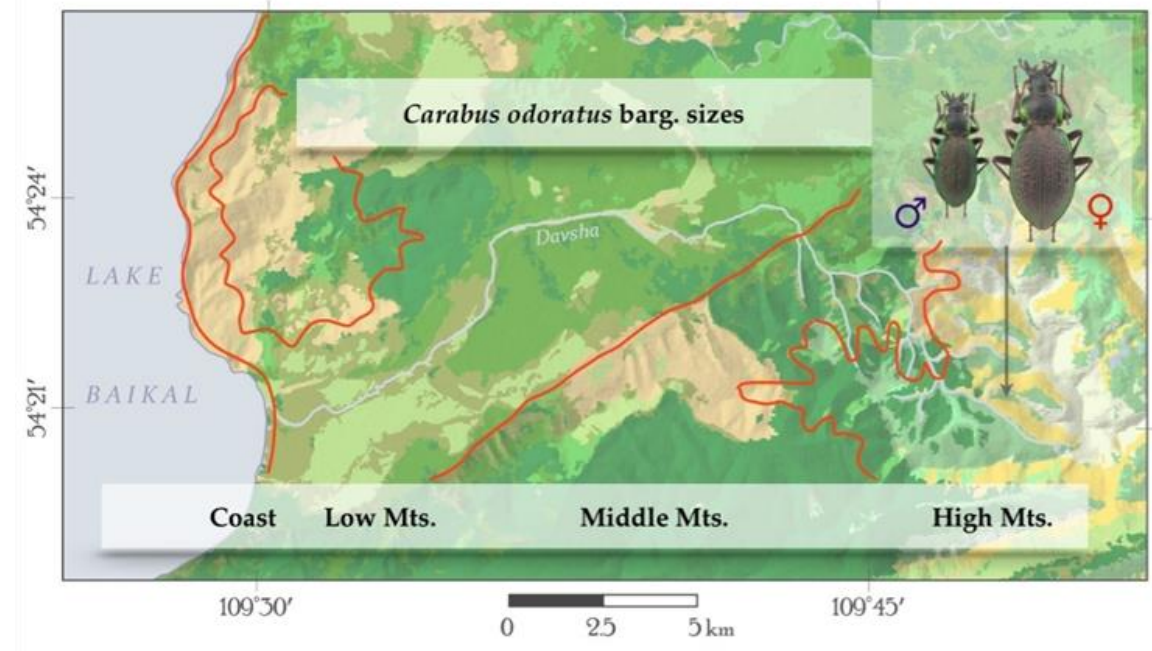

Keywords: Sexual Size Dimorphism; Ground Beetle; Altitude Gradient; RMA II.

\footnotetext{
${ }^{*}$ Corresponding author: Ananina Tatyana
} 


\section{Introduction}

The sexes of most biota differ fundamentally in morphology, ecology, and behavior [1]. Sexual differences in size (i.e. sexual size dimorphism; SSD), are particularly widespread among animal species [2, 3, 4, 5, 6]. In most cases, SSD is female-biased, although exceptions occur (particularly among birds and mammals [7, 8]. There are several hypotheses explaining the evolutionary origin of $\operatorname{SSD}[9,10,2,11,5]$. The most widely studied one is the sexual selection hypothesis, which proposes that sexual dimorphism emerges of competition for mates or mate choice [2]. It assumed that sexual selection generally favored male-biased SSD based on the competitive advantages for larger males during mate acquisition. Although female-biased SSD may also be a result of sexual selection (e.g. male preferences for larger females), ecological factors could also result in natural selection for sexual size dimorphism $[11,12,8]$. The role of natural selection for SSD is highlighted by the dimorphic niche hypothesis (or reproductive role hypothesis), which states that the differential reproductive roles of the sexes are associated with differential energetic costs [13], leading to different physical status $[10,2,14,15]$. These different optima are selective forces: sexual selection, fecundity selection, and viability selection [8]. In females of most invertebrate species, fecundity selection considered selecting for larger individuals, favoring larger clutch size, egg size, or offspring size [3,16]. Males may benefit from a smaller body size, which increases the potential to fertilize virgin females $[17,18]$. Other advantages for small males may be reduced ecological competition with females or greater mobility and agility facilitating the search for mates [19], as well as decreased predation risk and lower food requirements [20]. By contrast, sexual selection usually favors larger males $[13,21]$. The effect of viability selection on SSD remains poorly studied, although size-specific effects of predation, thermoregulation, etc. often assumed for constraining the potential size differences between the sexes [22, 23]. Hence, the differential effects of fecundity selection usually considered how the predominating power behind female-biased SSD [16, 23], whereas sexual selection is considered to support male-biased SSD [8, 24]. Female-biased SSD is common in a majority of insect species and in $95 \%$ of Orthopteran species $[18,24]$. Body size is generally a plastic character, strongly affected by environmental factors, as well as genetic preconditions [3]. Food quantity and quality, as well as temperature, affect growth and development $[6,25,26]$. The "temperature-size" rule states that, at lower temperatures, ectothermic individuals grow slower but attain larger body sizes than at higher temperatures [6, 26]. Therefore, insects face a trade-off and may respond to energetic limitations either by reducing their body size or by undergoing a prolonged developmental time. Phenotypic plasticity of body size can vary substantially between the sexes and can cause intraspecific variation [24, 27]. Given that the dimorphic niche hypothesis applies, one would expect that the sexes differ in their response towards environmental stresses, such as competition or limited energy supply to maximize their fitness [8]. Although females should aim to reach a maximum body size also under energetic limitation (which they may only reach by a longer developmental time), males should reduce body size to reach adulthood earlier. In many animal taxa, the allometry of body size among sexes varies in accordance with the pattern of SSD, it increases when males are the larger sex, but decreases with body size when females are larger than males $[4,28,29]$. These trends explained by greater evolutionary divergence and plasticity in male size, compared with female size, a pattern known as Rensch's rule $[4,29]$. Interestingly, in insects, allometric patterns have not always conformed to Rensch's rule. Notably, in solitary Hymenoptera, a consistent opposite trend has found, with variance in female size tending to be greater than the variance in male size [30, 31]. Though originally formulated to explain interspecific variation in sexual size dimorphism, a few studies have addressed the Rensch's rule by examining intraspecific, among-population variation in dimorphism, thereby testing the basic assumption that macroevolutionary patterns should be grounded in equivalent microevolutionary mechanisms. The results suggest, however, that Rensch's rule may or may not hold among populations within species $[32,33]$, depending on the taxon studied. The main idea of this paper was to analyze the data in relation to sexual size dimorphism (SSD). We tried to answer the following questions: (I) is SSD in C. odoratus femalebiased as in other carabids; (II) is SSD most pronounced in optimal biotopes; (III) does C. odoratus follow the Rensch's rule.

\section{Material and methods}

We conducted our study in the North East region of Baikal Lake (N 542 20'; E 109³0') (State Budgetary Establishment "Zapovednoe Podlemorie", Republic of Buryatia, Russian Federation). Beetles were sampled in 30-km high-altitude transect. It was in Davsha river valley and stretched from the coast of Baikal Lake to the bald Barguzin zone. The transect was divided into four plots designated as Coast (200-500 m from Baikal Lakeshore, 454-465 m upper-level sea), Low (12-17 km, 500-700 m), Medium (20-25 km, 701-1300 m) and High part of the range (25-30 km, $1301-1700 \mathrm{~m})$. Coast included biotopes with Bilberry cedar and Birch sparse grove. The bottom part of the mountain forest zone (Low Mountain) included biotopes with Blueberry larch and Red bilberry pine. Middle mountain biotopes included Bergenia aspen and Bilberry abies. High mountains - Birch sparse grove and Lichen tundra. We had conducted the previous research in this region when the majority of environmental factors investigated with thermographs, precipitation cylinders, soil thermometers Savinov. Snow depths measured in altitude belts before melting (in March) [34]. We had 
concluded that environmental conditions for ground beetles were less favorable at high altitudes and more favorable at low altitudes [35].

Carabus odoratus Motchulsky, 1844 distributed from the Yamal Peninsula and all around Siberia to Magadan area and Kamchatka Peninsula; in southern Siberia from Altai up to the Khabarovsk territories. The species is absent in the south of Far East Russia. The area of this species inhabited by many unequally differing populations. Some of the groups of populations, undoubtedly, should regard as subspecies. At the same time, the majority of populations constitute a continuous sequence of forms slightly different in size, coloration, and ratios, but it is hardly possible to consider these forms as subspecies. A considerable number of forms of $C$. odoratus described at present. The majority of intraspecific names treated as synonyms. The species has a large number of subspecies and local forms. In the Siberia and north of the Russian Far East, the species represented by 20 subspecies. The species occurs in the forest and mountain tundra at altitudes from 1500 to $2600 \mathrm{~m}$ above sea level [36]. In our study, we used Carabus odoratus barguzinicus Shil. 1996. It is the Baikal subspecies of Siberian species, endemic, and generalist in Barguzin ridge [37]. It is much higher in number than other carabids there and is considered to be the dominant species together with Pterostichus dilutipes Motsch., and Pterostichus montanus Motsch. [35]. Studied specimens identified using Shilenkov [37].

Our study took place in 2000 - 2017. Five pitfall traps were set at each site separated from each other by a minimum of $5 \mathrm{~m}$ to ensure the independence of samples. Each trap was $10 \mathrm{~cm}$ diameter, $15 \mathrm{~cm}$ in-depth, and contained

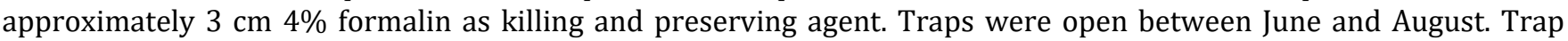
contents collected every 2 weeks and stored in $70 \%$ ethanol until processed.

The morphometric analysis made with a Leitz RS stereoscopic dissecting microscope at a magnification of 10 diameters, using a calibrated ocular grid with a scale interval of $0.1 \mathrm{~mm}$. For each specimen, six variables measured elytra length and width, pronotum length and width, head length, and the distance between eyes (Fig. 1).

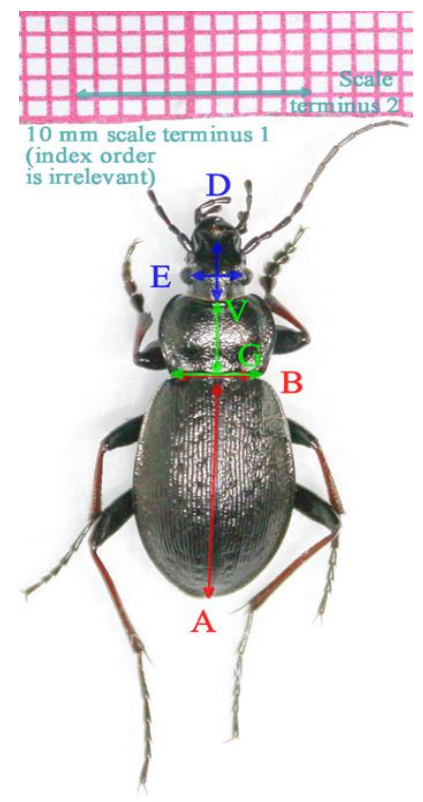

Figure 1 Studied morphometric characteristics in C. odoratus: A - elytra length, B - elytra width, V - pronotum length, $\mathrm{G}$ - pronotum width, D - head length, E - the distance between eyes.

To study the variation of sexual size dimorphism (SSD) we calculated the size dimorphism index [38] by dividing the trait size of the females by the trait size of males and subtracting one, resulting in negative SDI when male's trait is larger, and positive values of SDI when female`s trait is larger. To examine the dependence of SSD on environmental conditions male trait size plotted against female one separately for each trait. The scaling of SSD with body size analyzed using a Model II regression method: Reduced Major Axis (RMA) regression. Ordinary least squares (OLS) regression is inadequate for this type of analysis. We run the regressions using the software R, smart package [39]. The use of RMA regression of $\log 10$ (male size) on $\log 10$ (female size) is also justified because RMA is symmetric. It means that a single regression line defines the bivariate relationship independently of which variable is $\mathrm{X}$ and which is $\mathrm{Y}$, and this is the case for SSD comparisons: Rensch's rule supported when the slope $\beta$ RMA is significant $>1.0$, while slopes $<1.0$ signal its reversion. Slopes not significantly different from 1.0 indicate sexual isometry. Furthermore, a zero intercept implied 
a proportional increase of male and female sizes with conditions improving. A positive intercept indicated that female size increased relatively faster than male size, the former being then more sensitive to environmental conditions. A negative intercept indicated the opposite tendency.

These parameters allowed us to reach conclusions about the dependence of SSD on environmental conditions. In particular, it is easy to see that sex-related differences in sensitivity of body size to environmental conditions should lead to different female/male size ratios in different environments [27].

\section{Results}

In all altitude belts, females in C. odoratus were larger than males. Exceptions were elytra width and pronotum length at the coast (Fig. 2), where differences were not significant.
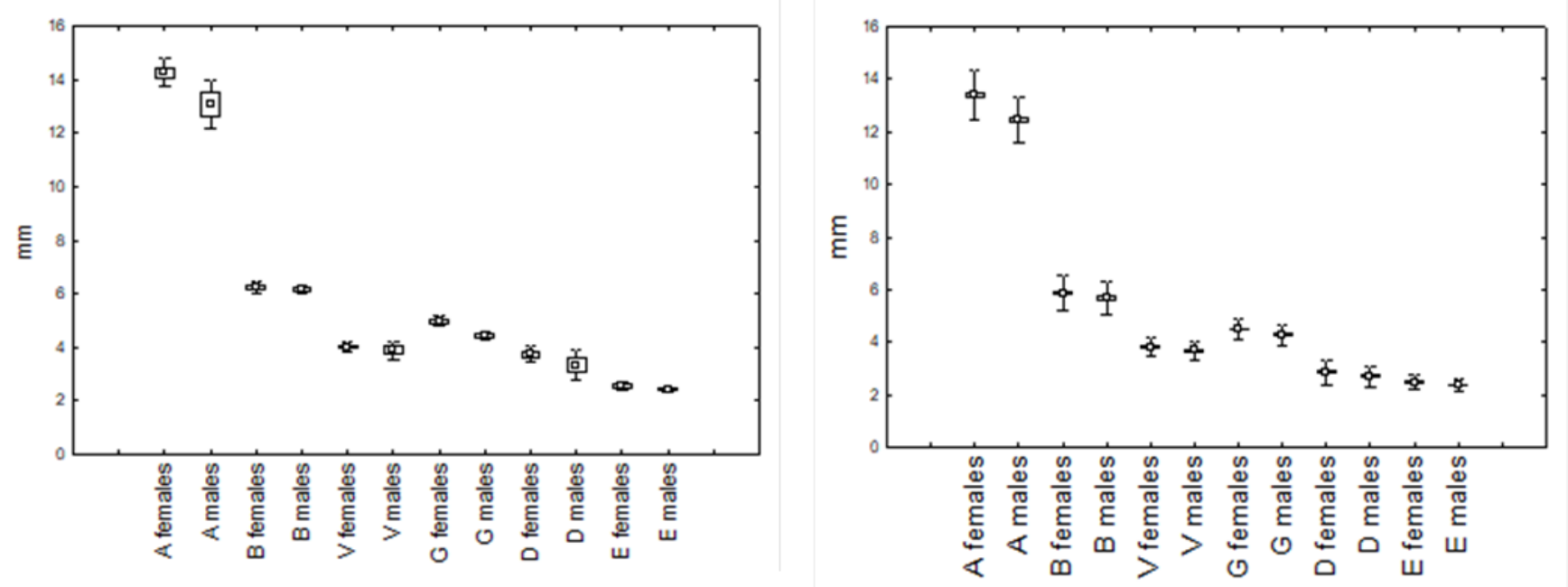

a

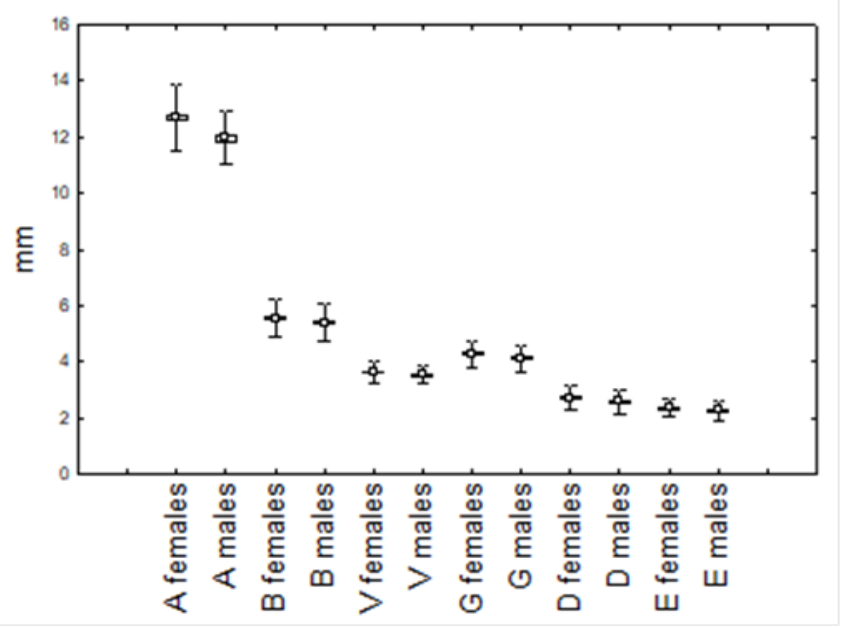

$\mathbf{C}$ b

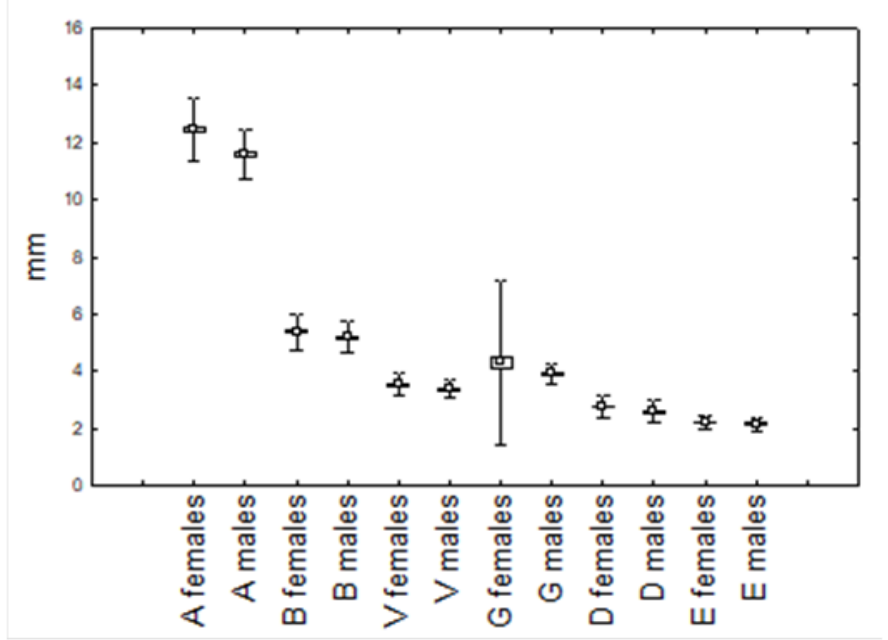

d

Figure 2 Descriptive statistics of morphometric traits in C. odoratus (Mean $\square$ Mean $\pm 2 * \mathrm{SE} I_{\text {Mean } \pm S D \text { ) }}$

Outliers * Extremes; A - elytra length, B - elytra width, C - pronotum length, D - pronotum width, E - head length, F - the distance between eyes; a Coast, b - Low mountains, $\mathrm{c}$ - Middle mountains, $\mathrm{d}$ - High mountains. 
When conducting RMA, all slopes were positive (Table 1, Fig. 3).

Table 1 Results of RMA regression in C. odoratust raits (p-level: $*<0.05, * *<0.01, * * *<0.001$ ).

\begin{tabular}{|c|c|c|c|}
\hline Altitude belt & Trait & Intercept & Slope \\
\hline \multirow[t]{6}{*}{ Coast } & Elytra length & -0.900 & 1.30 \\
\hline & Elytra width & 1.086 & $0.40^{*}$ \\
\hline & Pronotum length & 0.318 & 1.20 \\
\hline & Pronotum width & 0.279 & 0.75 \\
\hline & Head length & -0.749 & 1.49 \\
\hline & Distance between eyes & 0.484 & $0.44^{*}$ \\
\hline \multirow[t]{6}{*}{ Low Mountains } & Elytra length & 0.125 & $0.92^{* * *}$ \\
\hline & Elytra width & 0.098 & $0.93^{* * *}$ \\
\hline & Pronotum length & -0.04 & 0.99 \\
\hline & Pronotum width & 0.006 & $0.96^{* *}$ \\
\hline & Head length & 0.061 & $0.88^{* * *}$ \\
\hline & Distance between eyes & 0.009 & 0.96 \\
\hline \multirow[t]{6}{*}{ Middle Mountains } & Elytra length & 0.362 & $0.83^{* * *}$ \\
\hline & Elytra width & 0.045 & $0.96^{* *}$ \\
\hline & Pronotum length & -0.002 & 0.98 \\
\hline & Pronotum width & -0.032 & 0.99 \\
\hline & Head length & -0.131 & $1.07^{* *}$ \\
\hline & Distance between eyes & -0.094 & $1.06^{*}$ \\
\hline \multirow[t]{6}{*}{ High Mountains } & Elytra length & 0.378 & $0.82^{* * *}$ \\
\hline & Elytra width & 0.241 & $0.83^{* * *}$ \\
\hline & Pronotum length & 0.229 & $0.78^{* * *}$ \\
\hline & Pronotum width & 0.028 & $0.94^{* *}$ \\
\hline & Head length & -0.157 & $1.08^{* * *}$ \\
\hline & Distance between eyes & -0.0 .062 & 1.03 \\
\hline
\end{tabular}

That fact indicated that environmental conditions affected female and male size in the same direction, i.e. male size increased with female size increasing. Unambiguously such a result allowed to ranges traits in the samples according to the favorability of environmental conditions. Zero intercept implied a proportional increase of male and female trait sizes with conditions improving. In our case we concluded that all traits in coastal beetles (with the exception of elytra width), pronotum length and distance between eyes in low mountain beetles, pronotum traits in middle mountain beetles and distance between eyes in high mountain beetles varied isometrically in females and males, the latter having similar sensitivity to environmental conditions. However, regression curves in distance between eyes in middle mountain beetles and head length - in high mountain beetles had significant negative Intercepts. A negative intercept indicated that male size increased relatively faster than female size, the former being then more sensitive to environmental conditions. Hereby by those male traits of $\mathrm{C}$. odoratus were more sensitive to the environment in the corresponding biotope. In other traits in all high altitude belts, intercepts were positive, indicating that females by those traits were more sensitive to the environment. In this one, the values of SSD were significant. Those results supplemented Fig. 4: SSD was significant in two traits in coast beetles, four traits - in low-and-middle mountains beetles and in five traits - in high mountain beetles. 
Significant values of SSD (Fig. 3), where deviation from the isometric curve were significant marked by asterisks. It pronounced in the latter population. Out of 24 cases researched in 13 ones, the intercept was positive, indicating that in those traits females were more sensitive to the environment. As for traits, SSD in elytra parameters was significant in seven cases (out of eight researched), pronotum ones - in three cases (out of eight) and in head parameters - in five cases (out of eight). Thus, elytra length and width differed in females and males, more than other traits.
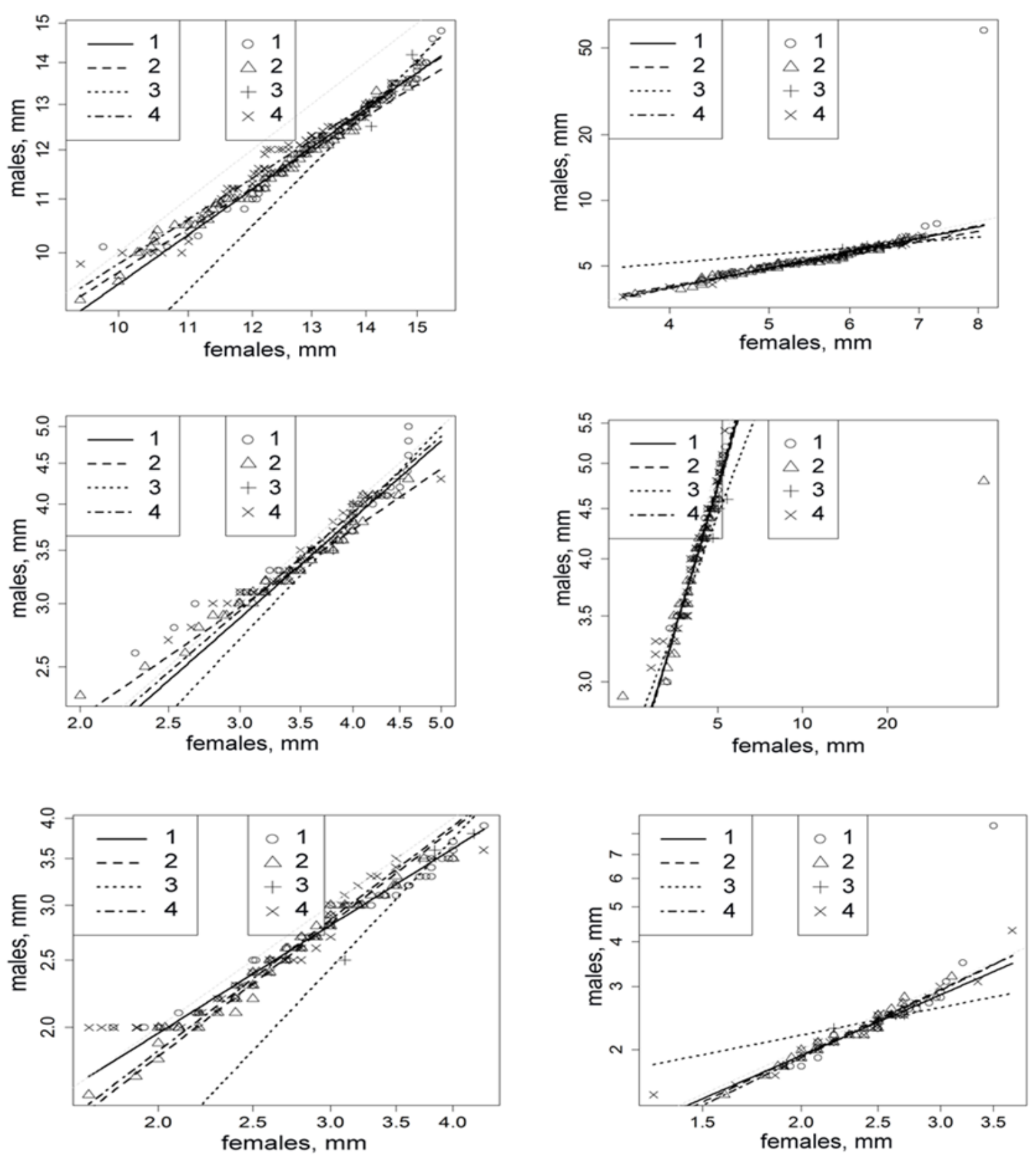

Figure 3 Results of RMA regression in C. odoratus traits (a - elytra length, b - elytra width, c - pronotum length, d pronotum width, $\mathrm{e}$ - head length, $\mathrm{f}$ - the distance between eyes). 1 - Coast, 2 - Low mountains, 3 - Middle mountains, 4 - High mountains. Circles cross, multiplication signs and triangles denote individuals measured. Grey dotted lines isometric relationship (slope $=1$ ). 


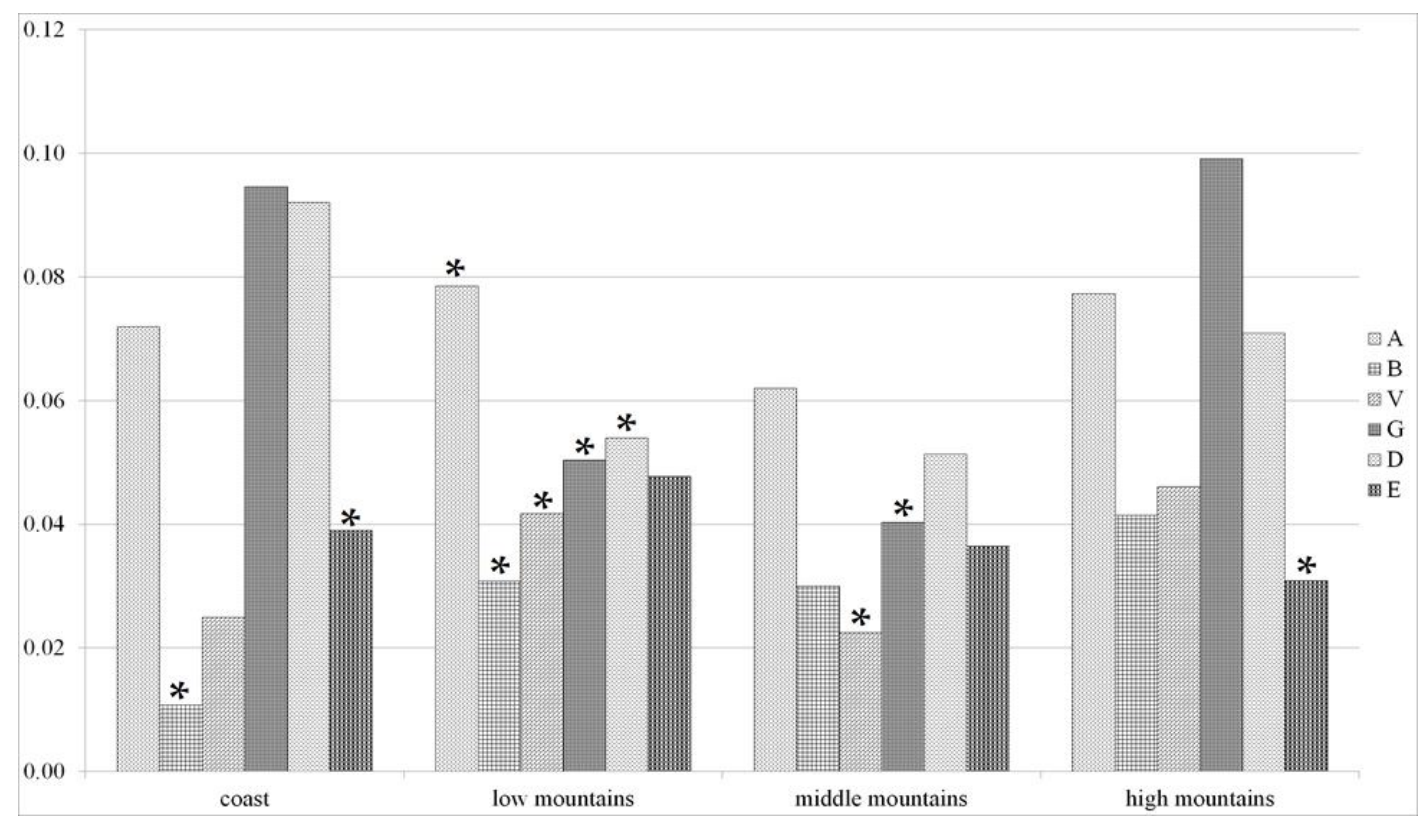

Figure 4 Values of SSD in different traits in C. odoratus. A - elytra length, B - elytra width, V - pronotum length, G pronotum width, D - head length, $\mathrm{E}$ - the distance between eyes.

\section{Discussion}

Though originally formulated to explain interspecific variation in sexual size dimorphism, some studies have addressed the Rensch's rule by examining intraspecific, among-population variation in dimorphism, thereby testing the basic assumption that macroevolutionary patterns should considered in equivalent microevolutionary mechanisms. The results suggest, however, the Rensch's rule may be [40,41,42] or not maybe among populations of different species [37]. One possible explanation for this discrepancy across taxonomic scales is the establishment of consistent genetic differences in dimorphism among populations, presumably due to sex-specific selection $[40,20]$. Perhaps this influenced by phenotypic plasticity [41], gene flow between populations [32], temporal variability in selection on male or female size [43], or not equivalence dimorphism arising from the generally very high genetic correlation between male and female size [9]. Macroevolutionary patterns of sexual size dimorphism across species less affected by these factors and should, better reflect evolutionary divergence in dimorphism over longer time scales [4, 41]. Nevertheless, identifying the putative microevolutionary mechanisms confirming or refuting the Rensch's rule among species requires studying variation in dimorphism in a greater number of species. Any general explanation should apply across taxonomic levels [4]. In our investigation, we found that SSD in C. odoratus was female-biased. It is common in carabids and other insects as well $[27,44]$. Contrary to other researchers, we studied not one, but six traits variation. If the only elytra length had been in study, we can confidently conclude that C. odoratus follows converse the Rensch's rule. Though in most cases Intercepts were positive, indicating that by most traits it is really is, in two cases (the distance between eyes at Middle mountain population and head length - in High mountain one) Intercepts were negative, indicating that by those traits and in those environments C. odoratus followed Rensch' rule. Then, firstly, we argue, that when investigating trends in traits variation, researchers would pay attention more than to the single trait. Secondly, if females are more sensitive to the environment in most traits, SSD in optimal conditions is more pronounced. In our study, it was the highest in low- and high altitudes. Indeed, owing to population density C. odoratus pine forest in Low mountains, and lichen tundra in High mountains were the favorable habitats. The plots on the Coast and in the Middle mountains appeared as adverse habitats [2014]. In addition, low altitude populations of C. odoratus sex ratio are female-biased [35] and the total body size of the beetles are larger than in other high-altitude vegetation belts [36].

The SSD severity in C. odoratus different traits is most evident in the parameters of elytra (7 cases out of 8) and in the parameters of the head ( 5 cases out of 8). SSD practically does not significant in pronotum size, perhaps by the reason of its evolutionary conservatism.

The literature on SSD variation in altitude gradient is scarce. Usually, researchers study body size variation in insects for both genders. They note decreasing or increasing body size in high elevation [47,48,49]. Our results in SSD variation differ from those of other researchers. For instance, body size in carrion beetles in females and males decreased towards 
the high altitudes, but SSD remained unchanged [50]. Female moths grew faster at high altitudes, but adult body sizes did not differ at low and high ones [51].We found in our study that:

- $\quad$ SSD in C. odoratus was female-biased;

- $\quad$ SSD was more pronounced in favorable habitats;

In most traits, $C$. odoratus follows the opposite of Rensch's rule.

\section{Conclusion}

Investigation of intra-specific SSD variation in insects is an unexplored area and this issue deserves attention in future ecological and evolutionary research. The patterns observed at the between-population could provide a clue to understanding the mechanisms observed at different environmental gradient scales. The values of SSD, characteristic to favorable and unattractive biotopes serve as biological indicators of habitat disturbance.

\section{Compliance with ethical standards}

\section{Acknowledgments}

We thank our colleagues in the Laboratory of Biomonitoring T. A. Gordienko, D. N. Vavilova nd O. P. Zhelezniyfor technical help during MS figuration. The study funded partially by the Fundamental Scientific Research Program (FSR) by the State Academy of Sciences for 2013-2020, a project№VI.51.1.2 (AAAA-A17-117011810035-6).

\section{Disclosure of conflict of interest}

All authors of the manuscript have no conflict of interests.

\section{Statement of informed consent}

Informed consent was obtained from all individual participants included in the study.

\section{References}

[1] Darwin C. (1859). On the origin of species. London, Murray, 1-199.

[2] Hedrick AV and Temeles EJ. (1989). Evolution of sexual dimorphism in animals: hypotheses and tests. Trends in Ecology \& Evolution, 4(5), 136 - 138.

[3] Honěk A. (1993). Intraspecific variation in body size and fecundity in insects: a general relationship. 0ikos, 1, 483 -492 .

[4] Fairbairn DJ. (1997). Allometry for sexual size dimorphism: pattern and process in the coevolution of body size in males and females. Annual review of ecology and systematic, 28(1), $659-687$.

[5] Temeles EJ, Pan IL, Brennan JL and Horwitt JN. (2000). Evidence for ecological causation of sexual dimorphism in a hummingbird. Science, 289(5478), $441-443$.

[6] Davidowitz G and Nijhout HF. (2004). The physiological basis of reaction norms: the interaction between growth rate, the duration of growth, and body size. Integrative and Comparative Biology, 44(6), $443-449$.

[7] Andersson MB. (1994). Sexual selection. Princeton University Press, Princeton, 1-405.

[8] Blanckenhorn WU. (2005). Behavioral causes and consequences of sexual size dimorphism. Ethology, 111(11), $977-1016$.

[9] Lande R. (1980). Sexual dimorphism, sexual selection, and adaptation in polygenic characters. Evolution, 34(2), $292-305$.

[10] Slatkin M. (1984). Ecological causes of sexual dimorphism. Evolution, 38(3), 622 - 630.

[11] Shine R. (1989). Ecological causes for the evolution of sexual dimorphism: a review of the evidence. The Quarterly Review of Biology, 64(4), $419-461$.

[12] Crowley PH. (2000). Sexual dimorphism with female demographic dominance: age, size, and sex ratio at 
[13] Savalli UM and Fox CW. (1998). Sexual selection and the fitness consequences of male body size in the seed beetle Statorlimbatus. Animal Behaviour, 55(2), 473 - 483.

[14] Shine R. (1991). Intersexual dietary divergence and the evolution of sexual dimorphism in snakes. The American Naturalist, 138(1), $103-122$.

[15] Hochkirch A, Gröning J and Krause S. (2007). Intersexual niche segregation in Cepero's Ground-hopper, Tetrixceperoi. Evolutionary Ecology, 21(6), 727 - 738.

[16] Reeve JP and Fairbairn J. (1999). Change in sexual size dimorphism, as a correlated response to selection on fecundity. Heredity, 83(6), $697-706$.

[17] Bidau CJ and Marti DA. (2007). Clinal variation of body size in Dichropluspratensis (Orthoptera: Acrididae): inversion of Bergmann's and Rensch's rules. Annals of the Entomological Society of America, 100(6), 850 - 860.

[18] Hochkirch A and Gröning J. (2008). Sexual size dimorphism in Orthoptera (sens. Str.): a review. Journal of Orthoptera Research, 1, 189 - 196.

[19] Kelly CD, Bussière LF and Gwynne DT. (2008). Sexual selection for male mobility in a giant insect with femalebiased size dimorphism. The American Naturalist, 172(3), 417 - 423.

[20] Blanckenhorn WU. (2000). The Evolution of body size: what keeps organisms small? The quarterly review of biology, 75(4), $385-407$.

[21] Wiklund C and Kaitala A. (1995). Sexual selection for large male size in a polyandrous butterfly: the effect of

[22] Bouteiller-Reuter and Perrin N. (2005). Sex-specific selective pressures on body mass in the greater whitetoothed shrew, Crocidura russula. Journal of evolutionary biology, 18(2), 290 - 300.

[23] Cox RM and Calsbeek R. (2010). Sex-specific selection and intraspecific variation in sexual size dimorphism. Evolution: International Journal of Organic Evolution, 64(3), 798 - 809.

[24] Stillwell RC, Blanckenhorn WU, Teder T, Davidowitz G and Fox CW. (2010). Sex differences in phenotypic plasticity affect variation in sexual size dimorphism in insects: from physiology to evolution. Annual review of entomology, 55, $227-245$.

[25] Atkinson D. (1994). Temperature and organism size: a biological law for ectotherms? Adv. Ecol. Res, 25,1 - 58.

[26] Angilletta MJ and Dunham AE. (2003). The Temperature-size rule in ectotherms: simple evolutionary explanations may not be general. The American Naturalist, 162(3), 332 - 342.

[27] Teder T and Tammaru T. (2005). Sexual size dimorphism with in species increases with body size in insects. Oikos, 108(2), 321 - 334.

[28] Abouheif E and Fairbairn DJ. (1997). Comparative analysis of allometry for sexual size dimorphism: assessing Rensch's rule. The American Naturalist, 149(3), 540 - 562.

[29] Rensch BE. (1950). Die Abhängigkeit der relative en Sexual differenz vonde rKörpergrösse. Bonner Zoologische Beiträge, 1, 58 - 69 .

[30] Blanckenhorn WU, Dixon AF, Fairbairn DJ, Foellmer MW, Gibert P, Linde KV, Meier R, Nylin S, Pitnick S, Schoff C and Signorelli M. (2006). Proximate causes of Rensch's rule: does sexual size dimorphism in arthropods result from sex differences in development time? The American Naturalist, 169(2), 245 - 257.

[31] Fairbairn DJ, Blanckenhorn WU and Székely T. (2007). Sex, size, and gender roles: Evolutionary studies of sexual size dimorphism. Oxford University Press, Oxford, UK, 1-290.

[32] Kraushaar U and Blanckenhorn WU. (2002). Population variation in sexual selection and its effect on size allometry in two dung fly species with contrasting sexual size dimorphism. Evolution, 56(2), 307 - 321.

[33] Quezada-Euán JJ, Sanabria-Urbán S, Smith C and Cuevadel-Castillo R. (2019). Patterns of sexual size dimorphism in stingless bees: Testing Rensch's rule and potential causes in highly eusocial bees (Hymenoptera: Apidae, Meliponini). Ecology and evolution, 9(5), 2688 - 2698.

[34] Ananin AA and Ananina T L. (2011). Long-term dynamics of birds and ground beetles population density in catena of Barguzinskiy ridge (Northern Pribaikalye). Findings of Samara Research Centre of Russian Academy of Sciences, 13(1/5), 1041-1044.

[35] Ananina TL. (2010). Carabid's dynamic of number in Mountain of North-East Prybaikalie. State nature biosphere reserve "Barguzinskyi". Buryat State University Publishing Department, Ulan-Ude, 1- 120. 
[36] Obydov D. (2006). A new subspecies of Carabus (Morphocarabus) odoratusMotchulsky, 1844 (Coleoptera, Carabidae) from Eastern Siberia. Mun. Entom. Zoology, 1(1), 149.

[37] Shilenkov VG. (1996). Ground Beetles of Carabus L. genus of Southern Siberia. Irkutsk University Publishing, Irkutsk, 1-88.

[38] Lovich JE and Gibbons JW. (1992). A review of techniques for quantifying sexual size dimorphism. Growth Development and Aging, 56, 269 - 281.

[39] R Development Team. (2015). R: A Language and environment for statistical computing. Vienna, Austria, 1 - 409.

[40] Fairbairn DJ and Preziosi RF. (1994). Sexual selection and the evolution of allometry for sexual size dimorphism in the water strider, Aquarius remigis. The American Naturalist, 144(1), $101-118$.

[41] Fairbairn DJ. (2005). Allometry for sexual size dimorphism: testing two hypotheses for Rensch's rule in the water strider Aquarius remigis. The American Naturalist, 166(4), 69 - 84.

[42] Young KA. (2005). Life-history variation and allometry for sexual size dimorphism in Pacific salmon and trout. Proceedings of the Royal Society B. Biological Sciences, 272(1559), 167 - 172.

[43] Sukhodolskaya RA, Saveliev AA and Muhammetnabiev TR. (2016). Sexual Dimorphism of Insects and Conditions of Its Manifestation. Research Journal of Pharmaceutical, Biological and Chemical Sciences, 7(2), 1992 - 2001.

[44] Ananina TL. (2015). Biotopic preferences of ground beetles (Carabidae, Coleoptera) of the Barguzin Ridge by the example of Carabus odoratus barguzinicus Shil. Eurasian Entomological Journal, 14(6), 511-517.

[45] Sukhodolskaya RA and Ananina TL. (2015). Altitudinal variation in population density, body size and morphometric structure in Carabus odoratus Shil, 1996 (Coleoptera: Carabidae). Acta Biol. Univ. Daugavp, 15(1), $179-190$.

[46] Ikeda H, Tsuchiya Y, Nagata N, Ito MT and Sota T. (2012). Altitudinal life cycle and body-size variation in ground beetles of the genus Carabus (subgenus Ohomopterus) in relation to the temperature conditions and prey earthworms. Pedobiologia, 55(2), 67 - 73.

[47] Cvetkovska-Gjorgjievska A, Hristovski S, Prelić D, Jelaska Ľ̌, Slavevska-Stamenković V and Ristovska M. (2017). Body size and mean individual biomass variation of ground-beetles community (Coleoptera: Carabidae) as a response to increasing altitude and associated vegetation types in mountainous ecosystem. Biologia, 72(9), 1059 $-1066$.

[48] Brehm G, Zeuss D and Colwell RK. (2018). Moth body size increases with elevation along a complete tropical elevational gradient for two hyper diverse clades. Ecography, 41, 1 - 11.

[49] Baranovská E and Knapp M. (2018). Steep converse Bergmann's cline in a carrion beetle: between-and withinpopulation variation in body size along an elevational gradient. Journal of Zoology, 304(4), 243 - 251.

[50] Bulgarella M, Trewick SA, Godfrey AJ, Sinclair BJ and Morgan-Richards M. (2015). Elevational variation in adult body size and growth rate but not in metabolic rate in the tree weta Hemideina crassidens. Journal of insect physiology, 75, $30-38$.

\section{How to cite this article}

Ananina T, Sukhodolskaya R and Saveliev A. (2020). Altitudinal variation of sexual size dimorphism in ground beetle Carabus odoratus Shill. GSC Biological and Pharmaceutical Sciences, 12(2), 27-36. 